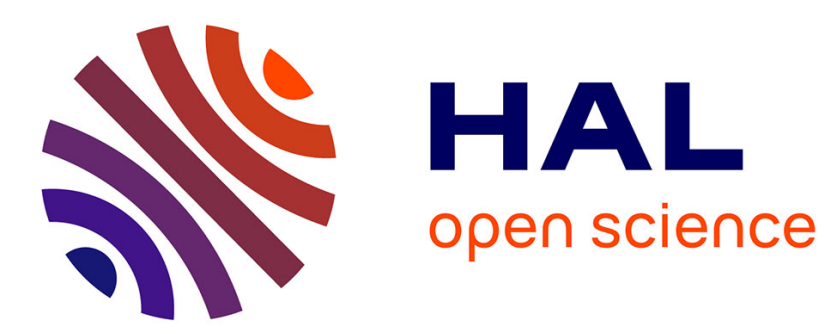

\title{
Modeling of Service Time in Public Organization Based on Business Processes
}

Larisa Bulysheva, Michael Kataev, Natalia Loseva

\section{To cite this version:}

Larisa Bulysheva, Michael Kataev, Natalia Loseva. Modeling of Service Time in Public Organization Based on Business Processes. 11th International Conference on Research and Practical Issues of Enterprise Information Systems (CONFENIS), Oct 2017, Shanghai, China. pp.3-11, 10.1007/978-3319-94845-4_1. hal-01888641

\section{HAL Id: hal-01888641 \\ https://hal.inria.fr/hal-01888641}

Submitted on 5 Oct 2018

HAL is a multi-disciplinary open access archive for the deposit and dissemination of scientific research documents, whether they are published or not. The documents may come from teaching and research institutions in France or abroad, or from public or private research centers.
L'archive ouverte pluridisciplinaire HAL, est destinée au dépôt et à la diffusion de documents scientifiques de niveau recherche, publiés ou non, émanant des établissements d'enseignement et de recherche français ou étrangers, des laboratoires publics ou privés.

\section{(c)(1)}

Distributed under a Creative Commons Attribution| 4.0 International License 


\title{
Modeling of Service Time in Public Organization Based on Business Processes
}

\author{
Larisa Bulysheva ${ }^{1} \square$, Michael Kataev², Natalia Loseva ${ }^{3}$ \\ ${ }^{1}$ Old Dominion University, Norfolk, USA \\ lbulyshe@odu.edu \\ 2 Tomsk State University of Control Systems and Radioelectronics, Tomsk, Russia \\ kataev.m@sibmail.com \\ ${ }^{3}$ Regional Branch of the Social Insurance Foundation, Tomsk, Russia \\ lonat@bk.ru
}

\begin{abstract}
Time is essence in all processes involved while providing customer service. Very often the duration of a specific service is regulated by the law. However, it is also affected by other external and internal factors. Quantitative approaches to model the service time and creating systems that support the workflow management process are vital. This paper proposes a model of business process analysis on the operational level for various service-oriented organizations (including governmental agencies). The model estimates time of rendering services for heavily regulated public organizations. The analysis of the obtained results is discussed, potential applications are identified, and future research directions are formulated.
\end{abstract}

Keywords: Process-Oriented Approach, Business Process, Mathematical Model, Time of Service, Workflow Management, Service, Public Organizations, Business Decision Making, Operational Level, Tactical and Strategic.

\section{Introduction}

The application of business processes in the description of any enterprise or institution allows to formalize and organize core business processes. It is the transparency of the description of workflows is a crucial factor that allows the institution to achieve specified improvements in its activities. The process of developing and formalizing business 
processes is quite laborious and complex task, which in the end allows us to achieve success in comparison with competitors. Business processes allow you to get some "portrait" of the main working routine functions that have certain parameters.

These parameters are related to the organizational structure, legislative and regulatory documents, cost and resource factors. All the factors can be divided into external and internal. Each of them, influence business processes and leads to their change. So, to maintain a given level of success, you must constantly modify business processes. This change is the only what is constant in modern business, and the change is an iterative process in nature. Extensive research is done in business process modeling, business performance management, and Enterprise Information systems [1, 2, 7, 8-11]. Number of effective algorithms based on Petri nets were developed to model service workflows [3- 6, 7].

The model of activity of the enterprises built with the help of the business process underlies the new direction of the "virtual enterprise" [2, 6, 12]. This approach allows us to build different variants of the model, depending on the possible modeling purposes. The objectives of the simulation associated with the control, management, forecasting, etc. For example, the control problem requires constructing a model that would enable a "big picture" of the institution and see the quality and quantity of the production processes in a temporary mode.

In general, the review processes of the institution through business processes (each of which has the specified parameters), allows us to build for the manager the equivalent of a "business game". The rules of the "games" allow the supervisor to observe each business process separately, as well as their combined activities. The quantitative aspect of this "game" leads to an understanding of the current state and the analysis of previous states, to assess the causes of the situation, also there is the possibility of forecasting.

Combination of technological aspects such as hardware, software and accumulated data, business processes, and people defines the needs for development of automated information system of control for public enterprise. Note, that this aspect is now rare considered in the literature in relation to public institutions providing services to general public. However, business performance management and measurement via identification of key performance indicators, usage of balanced scorecards, dashboards, and Six Sigma are well known. This allows the authors to reveal the importance of our research area and emphasize the value of formal methods development for modeling complex business processes and workflow management.

In this paper, we describe a mathematical model of transient processes of the public organizations activities at the lowest level (operational level) of business processes. We will start with a context diagram of business processes involved. Then, we will define the problems and formulate a mathematical model. Finally, we will conclude with examples of problem solved and discuss directions for future research. 


\section{Mathematical Model for Service Delivery Processes}

The functional model, which reflects the currently existing processes of the subject area (model "as is"), has been created. Figure 1 shows the context diagram, where the major entities and the flows of data involved are identified. The flows of data of the model processes of the subject area which reflects the boundaries of the model in width and describes most of the processes associated with the performance of services are included.

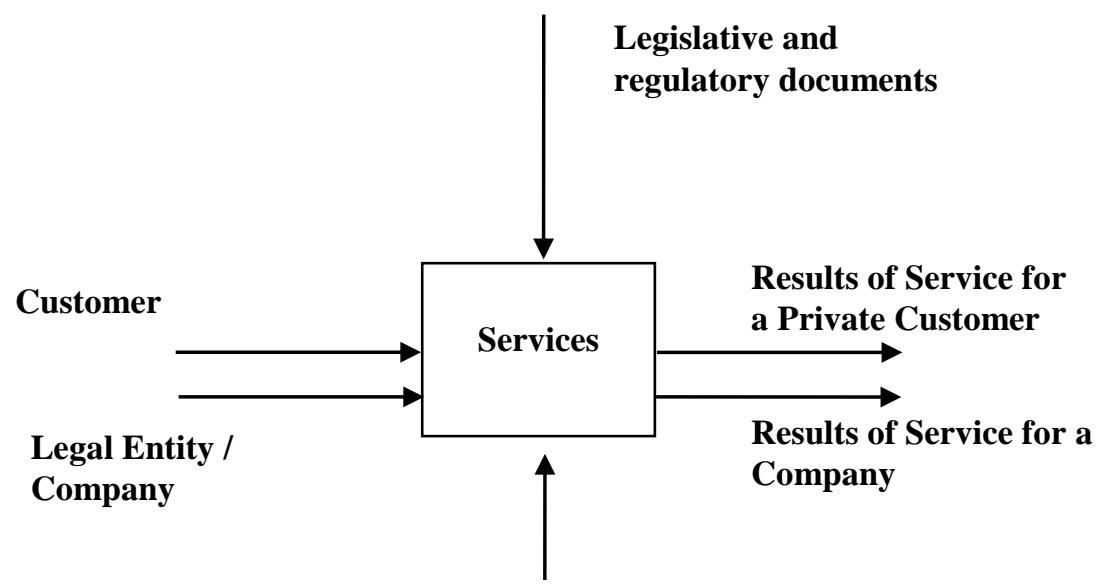

Service

Provider

Fig. 1. Model of service execution.

Management system is formed in accordance with the existing "Rules and regulations", where the service providers are "ministries and departments", "local government", "State, municipal and commercial institutions." The process of rendering services can be described as a sequence of phases implemented by key stakeholders. Structural diagram of this process is shown in Fig. 2. 



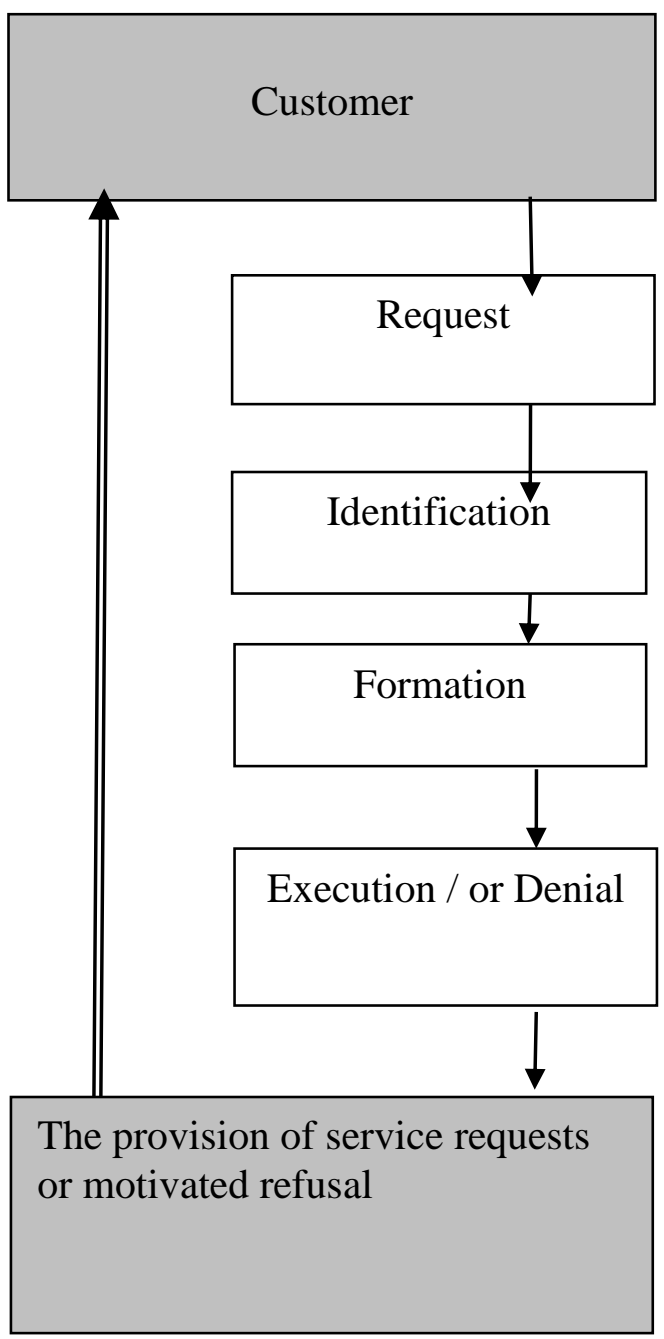


Fig. 2. Service rendering block diagram.

\section{$3 \quad$ Problem Definition}

Currently, there are many applications of business processes for solving problems of document management and business activities. However, there are no applications for management of the system mentioned above. There are only a few scientific papers devoted to this area of research. One reason for this is the fact that a qualitative approach is dominated in management activity of government institutions and quantitative is left out of researchers' attention.

Therefore, we propose to introduce the quantitative indicators, which are calculated based on business processes. Interdisciplinary integration of methods from operations research or management science including the linear programming models could be applied to formulate mathematical models for optimization of service provider operations in any business, including public.

Let's identify the main business-processes in providing services to public customers or legal entities. Typically, these activities are: "Service" or "Advice", or both. Figure. 3 shows the partitioning of the service provider day associated with the execution of certain business processes per request of services. Every day is unique due to qualification of the employees, the influence of external and internal factors. In a separate time period can be performed a variety of sequence of business processes (BP), rest (To) or running errands $(\mathrm{Tr})$, as shown in Figure 3.

\begin{tabular}{|c|c|c|c|c|c|}
\hline BP1 & \multicolumn{2}{|c|}{ To } & BP1 & To & \multicolumn{2}{c|}{ BP1 } \\
\hline BP2 & To & BP1 & To & \multicolumn{2}{|c|}{ Tr } \\
\hline BP2 & To & BP2 & \multicolumn{2}{|c|}{ To } & Tr \\
\hline
\end{tabular}

Service Provider 1 Service Provider 2 Service Provider 3

\section{Time}

Fig 3. The sequence of business processes execution in a workday. 
During process of solving problems of service management many situations arise which could affect the quality of services. Figure 3 shows that the control over the activities of specialists is quite difficult without introduction of automation systems. One of the elements, which is needed to be considered, is time of service providing. Calculation of this time should be separated from the breaks time and time to implement other duties such as supervisor requests.

We propose a general mathematical formulation of the problem of organization management for service provision. The schematic of the model is shown in Figure 4. This approach allows to see the process of providing services at different levels (operational, tactical and strategic) simultaneously.

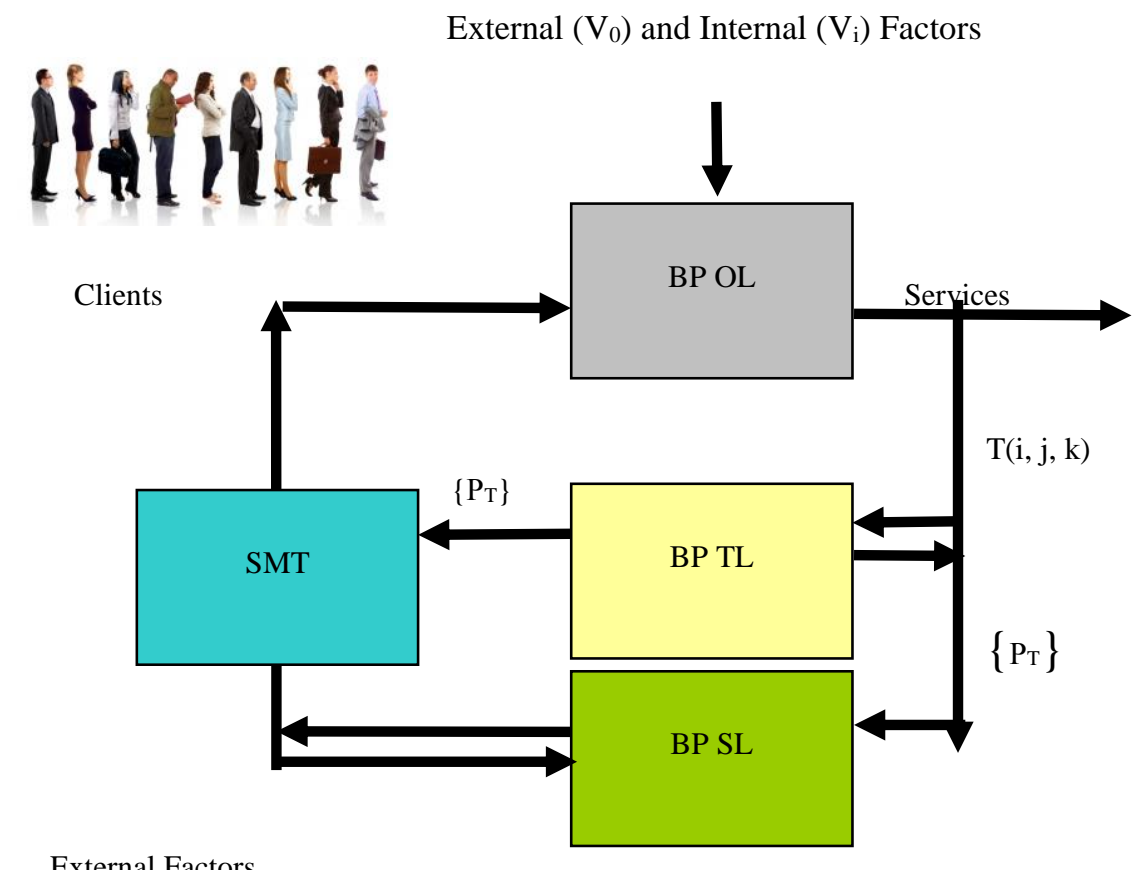

Fig. 4. Model of organization management for service provision.

Where BP OL - business processes on operational level,

BP TL - business processes on tactical level,

BP SL - business processes on strategic level,

SMT - system of generating the managerial action, 
$\left\{P_{T}\right\}$ - the tactical level, calculated based on temporal measurements,

$\mathrm{T}(\mathrm{i}, \mathrm{j}, \mathrm{k})$ the operational level.

The process of customer service, during the working time $T_{W}$ (work=8 hours) can be represented at the operational level in the form of the following models:

$$
T_{w}=T_{r}+T_{0}+T_{p}
$$

where $T_{r}$ - is the total time used for completion of customer request via all business processes,

$T_{0}$ - time is not associated with the business processes, and

$T_{p}$ - is the total time of performing supervisor requests.

Analyzing Figure 3, we can notice many different sequences in business processes that could take place while processing a customer request in a public institution. Management of employees' performance as the service providers to the public is complicated and currently poorly automated. The decision to control through usage of the special devices (cards) is currently present, however, it is not yet universally implemented. How this information could be used in management activities is the topic that needs to be investigated further and presented in the research literature.

For the solution of managerial tasks, you need to have a model that adequately, at a quantitative level describes the daily activities of the organizations. Working day description on the average values of $T_{w}, T_{r}, T_{0}, T_{p}$ is a well-known norm and enables the assessment activities at the tactical level (from weeks to months).

\section{$4 \quad$ Model Description}

Let's describe each element of the time model at the operational level of business processes in more details:

$$
T_{w}=\sum_{i=1}^{i=N}\left[\sum_{j=1}^{M}\left(T_{i, j}+T_{0 i, j}\right)+T_{p i}\right]
$$

where $\mathrm{N}-$ is a number of employees $(\mathrm{i}=1, \mathrm{~N})$ and

$\mathrm{M}$ - a number of services $(\mathrm{j}=1, \mathrm{M})$, 
$T_{i, j}$ - execution time of the business process associated with the service $\mathrm{j}$ by employee $\mathrm{i}$, $T_{0 i, j}$ - time between the processes, which are not directly associated with the implementation of business processes,

$T_{p i}$ - time that the i-th employee spends on executing other duties.

The execution time of business processes can be written as:

$$
T_{r i, j}=\sum_{k=1}^{k=K} \sum_{d=1}^{d=D}\left(t_{i, j, d, k, f}-t_{i, j, d, k, s}\right)
$$

where $\mathrm{K}$ - total number of clients and D - number of days of service,

$t_{i, j, d, k, f}, t_{i, j, d, k, s}-$ time completion of $\mathrm{f}$ (finish) and the start (s) of the process $\mathrm{s}$ of $\mathrm{j}$-th service by

the $\mathrm{i}$-th expert in day number $\mathrm{d}(\mathrm{d}=1, \mathrm{D})$.

The time between the business process services $\mathrm{k}$ and $(\mathrm{k}+1)$ customer is written like this:

$$
T_{0 i, j}=\sum_{k=1}^{k=K-1} \sum_{d=1}^{d=D}\left(t_{i, j, d, k+1, f}-t_{i, j, d, k, s}\right)
$$

where $\mathrm{K}$ - total number of clients and D - number of days of service provision for adoption of the report,

$t_{i, j, d, k, f}, t_{i, j, d, k, s}$ - time completion of $\mathrm{f}$ (finish) and the start (s) of the process $\mathrm{s}$ of $\mathrm{j}$-th service by the $\mathrm{i}$-th employee in day number $\mathrm{d}(\mathrm{d}=1, \mathrm{D})$.

The execution time of other duties of each employee i during the d-th day is calculated as follows:

$$
T_{p i}=\sum_{d=1}^{d=D} t_{p i, d}
$$

When calculating the total time of providing services, the next constrains must be considered:

1) $\left(t_{i, j, d, k, f}-t_{i, j, d, k, s}\right) \leq 15$ minutes (legally defined rule)

2) total working time that could be spent on providing services to population is specified as:

$$
\mathrm{T}_{\mathrm{rab}}=\mathrm{N} * \mathrm{D} * 480
$$


3) the waiting time in queue for customers must not exceed legally defined limits in minutes:

$$
\begin{aligned}
& \left(t_{r, i, j}-t_{0, i, j}\right) /(K D) \leq 30 \text { or } \\
& \left(K \times t_{p i}-t_{0 i, j}\right) /(K D) \leq 30
\end{aligned}
$$

\section{Solution of Managerial Problems Using Model}

There are various situations that arise from influence of external and/or internal factors during the actual organization activities [9]. The reaction to these situations by the management team is to bring the project (business processes) into a desirable state. Managerial decisions presented as the following steps:

(Plan $\rightarrow$ Business process $\rightarrow$ Measurement $\rightarrow$ Analysis $\rightarrow$ Solution) [9] are cyclical in nature. The purpose of which is to detect deviations of the plan parameters (in our case, normative values) from the real values at this time. In the event of deviations from the plan there is a need to take certain administrative actions to return the situation to the plan or norm.

To make an accurate decision, management needs to know the problem which cause the situation. Empirically, it is possible to evaluate a set of circumstances that are related to the problem, and then to find the options that at the legislative level allow you to build managerial decisions. Thus, in the presence of some deviations from the planned values, the management team appears able to know the set of management decisions for direct decision making. This intellectual component of the decision-making process should contribute to the objectivity and efficiency of decision.

It is well known that the working activities of any organization linked to the business processes that are designed to provide services to general population or legal entities. Each business process is characterized by a set of input and output parameters, service providers, and managerial decisions that are based on legal and other regulatory requirements. Every day for each employee the basic elements of the expected work activities are well known, and therefore, it becomes possible to assess the main temporal elements of their activities during the day and during each work time period. The model that is presented above is based on this assumption.

Note, that it is also possible to build a model, given the fact that the working activities of each employee with various business processes are essentially sequential steps. The sequence of these steps might be recorded. For example, if we know the beginning and end of each process or if we know even just beginning time of each business process, then it gives us quantitative material for analysis. The results of the 
analysis offer an opportunity, despite various changes within the process, to identify the parameters to help in decision making process. Please note, that the classical ways of decision making, if we consider such approaches as scheduling, calendar planning and others [9-11], cannot be applied in this case because the business processes served by the staff coming in a random order with a random duration (see Figure 3 ).

Considering that each public institution has its own specific personnel features, such as staff properties, age, qualification, culture, etc., which might be reflected in the style and types of managerial decision making, the use of the proposed model will allow to unify the decision making process, reduce the time and cost of rendering services, improve overall customer satisfaction, and to help in making higher quality and timely business decisions.

\section{$6 \quad$ Potential Applications and Future Research}

A specific feature of the temporary aspect of the organization of civil servants' activity is its intermittent nature, formed by the random arrival of different groups of clients, as well as by the large number of various orders coming from the management of different levels.

As a result, employees need to constantly adjust their plans and change time intervals in their activities:

1) the implementation of all business processes associated with customers in a given time limit;

2) performance (sometimes simultaneously with the main activity) of several orders with the same deadline and the same importance. These and other conditions for the temporary organization of civil servant activity are determined by the external and internal circumstances. The external frame of the temporal behavior is formed under the influence of external normatively given rhythms (in the activity of government bodies and civil servants) and the terms (execution of instructions). The internal frame of the temporary behavior of employees is related to solving the tasks of executing business processes for each of the clients according to the normatively defined timeframe.

When solving internal route tasks, important parts are cognitive, performing, communicative and emotional components for each employee (the components of the quality of the service). The timely completion of the assigned tasks of the state organization on rendering services to clients, in the presence of external and internal factors of the temporarily behavior, forces to involve new technologies. These technologies should make it possible to minimize the subjectivity in decision-making by the manager in the complex processes of daily routines allowing access to automated technologies.

Such technology may be the approach proposed in this paper, when the concept of a business process is introduced into the basis of the activity of a governmental organization. The system of business processes allows you to describe all the processes of 
labor when solving the main tasks of the organization, to evaluate objectively of the activities of the process executors and to perform forecasts. Our paper serves as the basis for the development of a formal approach that is considering uncertainties and varieties in the activities of the governmental organization presented above.

Future research will be focused on continuation of model development to make it even more adequate to the variety of business applications. It might be associated with considering additional parameters, such as qualifications of each service provider, the temporary features of the arrival of clients depending on various conditions, and other. As a result of modeling, we plan to provide recommendations for business process improvements, and to assist in developing of standardized protocols of employee actions with the goal to automate processing the main or routine operations.

Acknowledgments. The authors would like to thank the IFIP Confenis 2017, General Chairs: Dr. Zhou Zou and Dr. Li Rong Zheng, and IFIP WG 8.9 members for making this conference a great success.

\section{References}

1. $\mathrm{Xu}, \mathrm{L} .:$ Enterprise systems: State-of-the-art and future trends. IEEE Trans. Ind. Informat., 7(4), 630-640 (2011).

2. Kataev, M., Bulysheva, L., Emelyanenko, A., Emelyanenko, V.: Enterprise systems in Russia: 1992-2012. Enterprise Information Systems. 7(2), 169-186 (2013).

3. Viriyasitavat, W., Xu, L., Viriyasitavat, W.: Compliance Checking for RequirementOriented Service Work Flow Interoperations Transactions on Industrial Informatics, IEEE 10(2), 1469-1477 (2014).

4. Viriyasitavat, W., Xu, L., Viriyasitavat, W.: A New Approach for Compliance Checking in Service Workflows. IEEE Transactions on Industrial Informatics, 10(2), 1452-1460 (2014).

5. Van der Aalst, WMP.: The application of Petri nets to workflow management. J. Circuits Syst. Comput., 8(1), pp. 21-66 (1998).

6. Zisman M.: Representation, specification and automation of office procedures. Ph.D. dissertation, Wharton School of Business, Univ. Pennsylvania, Philadelphia, PA (1977).

7. Xu, L., Viriyasitavat, W.: A Novel Architecture for Requirement-oriented Participation Decision in Service Workflows. IEEE Transactions on Industrial Informatics, 10(2), 1478-1485 (2014).

8. Li, Y., Cao, L., Xu, L., Yin, J., Deng, S., Yin, Y., Wu, Z.: An Efficient Recommendation Method for Improving Business Process Modeling. IEEE Transactions on Industrial Informatics, 10(1), 502-513 (2014). 
9. Tan, W., Shen, W., Xu, L., Zhou, B., and Li, L.: A Business Process Intelligence System for Enterprise Process Performance Management. IEEE Transactions on SMC Part C, 38(6), 745-756 (2008).

10. Repin, V.: Business Processes. Modeling. Implementation. Management. Mann, Ivanov, Ferber, 5012 (2013) (in Russian).

11.Kataev, M.: Process oriented approach to enterprise management. Izvestia Tomskogo Polytehechnicheskogo Universiteta, 313(6), pp.20-23 (2012) (in Russian).

12. Kataev, M., Bulysheva, L., Xu., L.D., Loseva N.: Influence of external and internal environment on the governmental institutions decision making processes. In Proceedings of 22 International Scientific-Practical Conference, 2016, Tomsk, Russia, pp.50-54 (2016) (in Russian). 